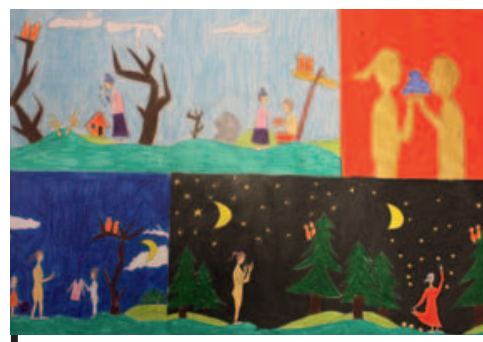

Kurzanamnese und

Wesentliches zum Verlauf

\section{Kommentar zur} Gestaltungstherapie und Bildinterpretation
Zum Titelbild

(C) Copyright Schön Klinik Roseneck, Prien

Bei der 19-jährigen Abiturientin besteht eine ausgeprägte depressive Stimmung, die von einer schweren Krebserkrankung des Vaters ausgelöst worden war, um den sie sich große Sorgen macht. Sie zieht sich zurück, vernachlässigt die Nahrungsaufnahme und lässt Mahlzeiten ausfallen, sodass sie immer mehr an Gewicht verliert. Mutter und Freundinnen sprechen sie darauf an, es gelingt ihr aber nicht, wieder zuzunehmen. In einem 8-wöchigen stationären psychiatrischen Aufenthalt verliert sie weiter an Gewicht und die depressive Symptomatik nimmt weiterhin zu. Bereits seit der Pubertät, ca. ab dem 13. Lebensjahr, fühlt sie sich unwohl, selbstunsicher und zieht sich zurück. Seit der Krankheit des Vaters hat sie den Eindruck, für die Familie verantwortlich zu sein und will selbst niemandem zur Last fallen. Sie versucht nach außen hin, weiter zu funktionieren. Eine mehrmonatige Beziehung zu einem deutlich älteren Mann gestaltet sich unglücklich, da sie ihre eigenen Grenzen und Bedürfnisse nicht durchzusetzen vermag.

Wir diagnostizieren eine schwere depressive Episode sowie eine atypische Anorexia. In der Klinik ist es für die Patientin besonders wichtig, ihre Gefühle wieder wahrzunehmen und diese auch zuzulassen. In Familiengesprächen gelingt es ihr, ihre Bedürfnisse und Wünsche konkreter zu kommunizieren. In kleinen Schritten festigt sich ihr Selbstwertgefühl und sie traut sich mehr zu. Die Gestaltungstherapie ist für sie eine wichtige Maßnahme, um Wünsche und Bedürfnisse auch nonverbal zum Ausdruck zu bringen. Im Laufe der Behandlung gelingt eine Stabilisierung sowohl des Essverhaltens als auch der Stimmungslage.

Das Titelbild zeigt eine am Ende des Klinikaufenthalts erlebte Situation der Patientin. In einer Serie von 6 Bildern erzählt sie, wie sie sich bewusst Zeit für sich nimmt und wieder lernt, das Baden im See zu genießen. Besonders in diesem Moment wird ihr bewusst, dass dies für sie unvorstellbar ist, solange die Essstörung so viel Raum einnimmt.

Die Gestaltungstherapie stellt sich als Möglichkeit dar, von Anfang an ihre individuelle Symbolsprache auszudrücken. Selbst wenn sie immer wieder positive Rückmeldung zu ihren Bildern bekommt, besitzt sie zunächst wenig Vertrauen in ihre Fähigkeiten und neigt dazu, sich abzuwerten. Dabei wird ihr klar, welch hohe Erwartungen sie an sich selbst stellt und diese im Kontext der vermeintlichen Familienerwartungen sieht. Nachdem sie ihren Zugang zum kreativen Arbeiten (Wahrnehmen statt Produzieren) modifiziert und ihre Einstellung sich selbst gegenüber (Fürsorge statt Abwertung) hinterfragt hat, wählt sie das Kindheitsmärchen «Sterntaler» als gestalterisches Vorbild, das bedeutsam für ihr Lebensskript ist (kleines Bild). Diese bildnerische Methode ermöglicht es ihr, den eigenen Lebensplan mit dessen typischen Elternbotschaften kennen, aber auch bei Bedarf korrigieren zu lernen. Abgesehen davon, dass das perfektionistische Erstellen dieser Bildergeschichte viel Zeit, Kraft und Anstrengung in Anspruch nimmt, werden ihr auch inhaltlich schwierige Themen bewusster und klarer. Schon in frühesten Jahren ist der familiäre Zusammenhalt von materiellen Aspekten, aber auch von emotionalem Verzicht, ausgeglichen durch Leistung und Vernunft, geprägt - ein Lebensweg, den sie bislang nicht anzuzweifeln wagte. Die in der Auseinandersetzung aufkommenden Gefühle machen ihr deutlich, dass auch andere Anteile in ihr Raum benötigen. Um diese Anteile zu integrieren, schreibt sie ihr «von außen herangetragenes» Lebensskript um und entwickelt ihr eigenes, ausgehend von einer zuvor erlebten angenehmen Situation (Titelbild). Zum ersten Mal fühlt sie sich beim Malen nicht unter Druck; sie darf sich für ihr Bild, das viel spontaner und intuitiver entsteht, sogar loben. In dieser Situation spürt sie die Atmosphäre und ihre Körperlichkeit als etwas Angenehmes und Genussvolles. Das Bild lässt sie diese wertvolle Erfahrung immer wieder erleben und macht ihr deutlich, wie sie jetzt beginnt, die Weichen für ihren neuen Lebensabschnitt zu stellen. Die Essstörung tritt in den Hintergrund und Selbstvertrauen und eigene Bedürfnisse bahnen sich ihren Weg.

Klinik Roseneck, Prien am Chiemsee Abteilung Gestaltungstherapie Carl Leibl / Jasmine Follert / Karin von Külmer 